\title{
Correlation between polymorphisms in microRNA-regulated genes and cervical cancer susceptibility in a Xinjiang Uygur population
}

\author{
Jing Fang ${ }^{1, *}$, Ying Li ${ }^{2, *}$, Jiayi Zhang ${ }^{3,4}$, Mengdan Yan ${ }^{3,4}$, Jingjie $\mathrm{Li}^{3,4}$, Shan Bao ${ }^{5}$ and \\ Tianbo Jin ${ }^{3,4}$ \\ ${ }^{1}$ Department of Obstetrics and Gynecology, The First Affiliated Hospital of Xi'an Jiaotong University, Xi'an, Shaanxi 710061, \\ China \\ ${ }^{2}$ Department of Radiology, The First Affiliated Hospital of Xi'an Medical University, Xi'an, Shaanxi 710077, China \\ ${ }^{3}$ Key Laboratory of Resource Biology and Biotechnology in Western China (Northwest University), Ministry of Education, \\ School of Life Sciences, Northwest University, Xi'an, Shaanxi 710069, China \\ ${ }^{4}$ Xi'an Tiangen Precision Medical Institute, Xi'an, Shaanxi 710075, China \\ ${ }^{5}$ Clinic of Gynecology and Obstetrics, Hainan Provincial People's Hospital, Haikou 570102, China \\ *These authors have contributed equally to this work and should be considered as joint first authors \\ Correspondence to: Shan Bao, email: shanbaohainan@163.com \\ Tianbo Jin, email: jintianbo@gmail.com \\ Keywords: association study, cervical cancer, MicroRNA gene, single nucleotide polymorphisms (SNPS) \\ Received: November 14, $2016 \quad$ Accepted: February 15, $2017 \quad$ Published: March 07, 2017 \\ Copyright: Fang et al. This is an open-access article distributed under the terms of the Creative Commons Attribution License \\ (CC-BY), which permits unrestricted use, distribution, and reproduction in any medium, provided the original author and source \\ are credited.
}

\section{ABSTRACT}

We explored the correlation between single nucleotide polymorphisms (SNPS) and susceptibility to cervical cancer (CC) in a Xinjiang Uygur population. Ten SNPs in eight miRNA-regulated genes were selected for analysis. Odds ratios (ORs) and $95 \%$ confidence intervals ( $95 \%$ CIs) were calculated using unconditional logistic regression analysis. Multivariate logistic regression analysis was used to detect correlations between SNPs and CC. We found that minor allele "C" of rs512715 in NEAT1 was associated with an increased risk of $\mathrm{CC}$ in the allele, codominant, dominant, overdominant and log-additive models. Minor allele "C" of rs4777498 in CELF6 was associated with an increased risk of CC in the recessive model. Minor allele "C" of rs3094 in RNASE4 was associated with increased risk of $\mathrm{CC}$ in the allele, dominant and log-additive models. In clinical stage III/IV CC patients, minor allele "C" of rs3094 in RNASE4 and minor allele "C" of rs8004334 in JDP2 were associated with increased risk. In subtype squamous carcinoma CC patients, minor allele " $\mathrm{C}$ " of rs512715 in NEAT1 and minor allele "C" of rs3094 in RNASE4 were associated with increased risk. In subtype adenocarcinoma CC patients, minor allele "C" of rs3094 in RNASE was associated with increased risk.

\section{INTRODUCTION}

Cervical cancer (CC) is the fourth most common malignancy in women, with 528,000 occurrences and 266,000 deaths in 2012 [1]. More than $85 \%$ of CC occurs in developing regions such as Eastern Africa, Melanesia, and Southern and Central Africa, where cervical CC accounts for more than $60 \%$ of gynecological cancers [2]. Cervical cancer is mainly attributable to human papillomaviruses (HPVs or PVs), which belong to the large Papillomaviridae family [1]. HPV particles include an approximately 8000-bp, double-stranded, closed circular DNA harboring eight genes [3].

Although previous studies have reported several biomarkers of $\mathrm{CC}$, including $\mathrm{p} 16^{\mathrm{INK} 4 \mathrm{a}}$ and $\mathrm{Ki}-67$, few have investigated the relationship between $\mathrm{CC}$ risk and microRNA (miRNA)-regulated genes, including CDK6, PTEN and NEAT1, among others. MiRNAs are small ( $\sim 19-25$ nucleotides) non-coding RNA sequences that regulate gene expression through translational 
Table 1: Basic information on the SNPs examined in this study

\begin{tabular}{|c|c|c|c|c|c|c|c|c|c|c|c|c|c|}
\hline \multirow{3}{*}{$\begin{array}{l}\text { SNPs } \\
\text { rs2285332 }\end{array}$} & \multirow{3}{*}{ MiRNA } & \multirow{3}{*}{$\begin{array}{c}\text { Gene } \\
\text { CDK6 }\end{array}$} & \multirow{3}{*}{$\begin{array}{c}\text { Chr } \\
\operatorname{chr} 7\end{array}$} & \multirow{3}{*}{$\begin{array}{c}\text { Band } \\
7 \mathrm{q} 21.2\end{array}$} & \multirow{3}{*}{$\begin{array}{c}\text { Role } \\
\text { 3' UTR }\end{array}$} & \multirow{3}{*}{$\frac{\text { Alleles }}{\mathrm{C} / \mathrm{G}}$} & \multicolumn{2}{|c|}{ MAF } & \multirow{3}{*}{$\begin{array}{c}\text { HWE } \\
\boldsymbol{p} \\
0.008\end{array}$} & \multirow{3}{*}{$\begin{array}{c}\text { OR } \\
1.310\end{array}$} & \multirow{2}{*}{\multicolumn{2}{|c|}{$95 \% \mathrm{CI}$}} & \multirow{3}{*}{$\begin{array}{c}\boldsymbol{p} \\
0.028\end{array}$} \\
\hline & & & & & & & \multirow{2}{*}{$\frac{\text { casae }}{0.504}$} & \multirow{2}{*}{$\frac{\text { control }}{0.437}$} & & & & & \\
\hline & & & & & & & & & & & 1.029 & 1.669 & \\
\hline rs701848 & hsa-miR-23b & PTEN & $\operatorname{chr} 10$ & $10 \mathrm{q} 23.31$ & 3' UTR & $\mathrm{T} / \mathrm{C}$ & 0.536 & 0.489 & 0.192 & 1.207 & 0.948 & 1.536 & 0.126 \\
\hline rs 11202607 & hsa-miR-23b & PTEN & $\operatorname{chr} 10$ & $10 q 23.31$ & 3' UTR & $\mathrm{T} / \mathrm{C}$ & 0.079 & 0.065 & 0.022 & 1.235 & 0.774 & 1.969 & 0.375 \\
\hline rs680413 & hsa-mir-342-3p & NEAT1 & $\operatorname{chr} 11$ & $11 \mathrm{q} 13.1$ & 5' UTR & $\mathrm{G} / \mathrm{T}$ & 0.130 & 0.128 & 0.013 & 1.013 & 0.707 & 1.452 & 0.943 \\
\hline rs512715 & hsa-mir-342-3p & NEAT1 & $\operatorname{chr} 11$ & $11 q 13.1$ & 5' UTR & $\mathrm{C} / \mathrm{G}$ & 0.326 & 0.263 & 0.221 & 1.354 & 1.039 & 1.764 & 0.025 \\
\hline rs1133822 & hsa-mir-342-3p & LOC105372481 & $\operatorname{chr} 19$ & $19 q 13.43$ & - & $\mathrm{G} / \mathrm{A}$ & 0.302 & 0.328 & 1.000 & 0.885 & 0.682 & 1.147 & 0.355 \\
\hline rs4777498 & hsa-mir-375 & CELF6 & $\operatorname{chr} 15$ & $15 q 23$ & 3' UTR & $\mathrm{C} / \mathrm{A}$ & 0.202 & 0.184 & 0.693 & 1.124 & 0.829 & 1.525 & 0.452 \\
\hline rs3094 & hsa-mir-590-5p & RNASE4 & chr14 & $14 q 11.2$ & 3' UTR & $\mathrm{C} / \mathrm{T}$ & 0.360 & 0.293 & 0.476 & 1.359 & 1.051 & 1.758 & 0.019 \\
\hline rs8004334 & hsa-mir-590-5p & JDP2 & $\operatorname{chr} 14$ & $14 q 24.3$ & Promoter & $\mathrm{C} / \mathrm{T}$ & 0.435 & 0.379 & 0.615 & 1.263 & 0.988 & 1.614 & 0.062 \\
\hline rs3733839 & hsa-mir-590-5p & LOC153684 & $\operatorname{chr} 5$ & $5 \mathrm{p} 12$ & 5' UTR & $\mathrm{C} / \mathrm{G}$ & 0.265 & 0.273 & 0.293 & 0.961 & 0.732 & 1.262 & 0.774 \\
\hline
\end{tabular}

Abbreviations: SNPs: Single nucleotide polymorphisms; MiRNA: microRNA; Chr: chromosome; MAF: Minor allele frequency; HWE: Hardy-Weinberg equilibrium; OR: Odds ratio; CI: Confidence interval.

$p$-values were calculated using Pearson's $\chi^{2}$ test. Values of $p<0.05$ were considered statistically significant.

suppression accomplished through direct and/or triggered degradation of coding mRNAs mediated through binding to complementary sequences in the $3^{\prime}$ untranslated region (UTR) [4]. In this way, miRNAs play key roles in a variety of biological process, including cell apoptosis, proliferation, differentiation, development and tumorigenesis, which are involved in the pathogenesis of a variety of ailments, including cancer, nephropathy and renovascular disease [5-7]. Consequently, how miRNA-regulated genes affect $\mathrm{CC}$ risk would seem to be a potentially meaningful investigation. We therefore investigated the relationships between single nucleotide polymorphisms (SNPs) in miRNA-regulated genes and the risk of CC. In the present case-control study, we selected 10 SNPs in eight miRNA-regulated genes and performed a comprehensive association analysis in a Xinjiang Uygur population.

\section{RESULTS}

The basic information on the 10 SNPs examined in this study is summarized in Table 1 . We found that rs2285332 $(p=0.008), \operatorname{rs} 11202607(p=0.022)$ and rs680413 ( $p=0.013)$ deviated from the Hardy-Weinberg Equilibrium $(p<0.05)$, and were excluded from our analysis. We found two SNPs were significantly associated with CC (rs512715, NEAT1, OR $=1.354,95 \%$ CI: 1.039 $1.764, p=0.025 ;$ rs 3094, RNASE4, OR $=1.359,95 \% \mathrm{CI}$ : $1.051-1.758, p=0.019)$.

We then conducted an unconditional logistic regression analysis, and the positive results are illustrated in Table 2. We found three SNPs that were associated with increased $\mathrm{CC}$ risk in different models. The minor allele "C" of rs512715 increased CC risk in the codominant (OR
$=1.56,95 \% \mathrm{CI}: 1.09-2.24, p=0.044)$, dominant $(\mathrm{OR}=$ $1.55,95 \% \mathrm{CI}: 1.10-2.18, p=0.012)$, overdominant $(\mathrm{OR}=$ $1.46,95 \% \mathrm{CI}: 1.03-2.08, p=0.032)$ and log-additive (OR $=1.34,95 \%$ CI: $1.03-1.75, p=0.027)$ models. The minor allele "C" of rs4777498 increased CC risk in the recessive model $(\mathrm{OR}=2.40,95 \% \mathrm{CI}: 1.01-5.70, p=0.041)$. And the minor allele "C" of rs3094 increased CC risk in dominant $(\mathrm{OR}=1.47,95 \% \mathrm{CI}: 1.04-2.08, p=0.027)$ and log-additive $(\mathrm{OR}=1.35,95 \% \mathrm{CI}: 1.04-1.74, p=0.021)$ models.

The associations between SNPs and different clinical stages and CC subtypes were assessed, and the positive results are illustrated in Table 3. In clinical stage III/IV patients, we found rs3094 (OR $=1.51,95 \% \mathrm{CI}$ : $1.06-2.14, p=0.021)$ and $\mathrm{rs} 8004334(\mathrm{OR}=1.60,95 \% \mathrm{CI}$ : $1.15-2.24, p=0.006)$ to be associated with an increased $\mathrm{CC}$ risk. In subtype squamous carcinoma patients, we found $\mathrm{rs} 512715(\mathrm{OR}=1.37,95 \% \mathrm{CI}: 1.05-1.79, p=$ $0.021)$ and $\operatorname{rs} 3094(\mathrm{OR}=1.31,95 \% \mathrm{CI}: 1.01-1.70, p=$ 0.043 ) to be associated with an increased CC risk. And in subtype adenocarcinoma patients, we found rs3094 (OR = 4.02, 95\% CI: $1.11-11.24, p=0.004)$ to be associated with an increased $\mathrm{CC}$ risk.

\section{DISCUSSION}

In the present study, we found that four SNPs belonging to four miRNA-regulated genes were associated with CC risk. These were rs512715 in NEAT1 regulated by hsa-mir-342-3p, rs4777498 in CELF6 regulated by hsamir-375, and rs3094 in RNASE4 and rs8004334 in JDP2, both regulated by hsa-mir-590-5p.

In humans, miRNAs are transcribed by RNA polymerase II in the nucleus as pri-miRNAs, which may contain two or more mature miRNAs. Subsequently, 
Table 2: Unconditional logistic regression analysis of the association between SNPs and CC risk

\begin{tabular}{|c|c|c|c|c|c|c|c|c|}
\hline SNPs & Model & Genotype & Controls n (\%) & Cases n (\%) & OR $(95 \% \mathrm{CI})$ & $p$ & AIC & BIC \\
\hline \multirow{10}{*}{ rs512715 } & \multirow{3}{*}{ Codominant } & $\mathrm{G} / \mathrm{G}$ & $159(55.8 \%)$ & $111(44.9 \%)$ & 1 & \multirow{3}{*}{0.044} & \multirow{3}{*}{734.5} & \multirow{3}{*}{747.4} \\
\hline & & $\mathrm{C} / \mathrm{G}$ & $102(35.8 \%)$ & $111(44.9 \%)$ & $1.56(1.09-2.24)$ & & & \\
\hline & & $\mathrm{C} / \mathrm{C}$ & $24(8.4 \%)$ & $25(10.1 \%)$ & $1.49(0.81-2.75)$ & & & \\
\hline & \multirow{2}{*}{ Dominant } & $\mathrm{G} / \mathrm{G}$ & $159(55.8 \%)$ & $111(44.9 \%)$ & & \multirow{2}{*}{0.012} & \multirow{2}{*}{732.5} & \multirow{2}{*}{741.1} \\
\hline & & $\mathrm{C} / \mathrm{G}-\mathrm{C} / \mathrm{C}$ & $126(44.2 \%)$ & $136(55.1 \%)$ & $1.55(1.10-2.18)$ & & & \\
\hline & \multirow{2}{*}{ Recessive } & $\mathrm{G} / \mathrm{G}-\mathrm{C} / \mathrm{G}$ & $261(91.6 \%)$ & $222(89.9 \%)$ & 1 & \multirow{2}{*}{0.5} & \multirow{2}{*}{738.3} & \multirow{2}{*}{746.9} \\
\hline & & $\mathrm{C} / \mathrm{C}$ & $24(8.4 \%)$ & $25(10.1 \%)$ & $1.22(0.68-2.20)$ & & & \\
\hline & \multirow{2}{*}{ Overdominant } & G/G-C/C & $183(64.2 \%)$ & $136(55.1 \%)$ & 1 & \multirow{2}{*}{0.032} & \multirow{2}{*}{734.2} & \multirow{2}{*}{742.7} \\
\hline & & $\mathrm{C} / \mathrm{G}$ & $102(35.8 \%)$ & $111(44.9 \%)$ & $1.46(1.03-2.08)$ & & & \\
\hline & Log-additive & --- & --- & --- & $1.34(1.03-1.75)$ & 0.027 & 733.9 & 742.5 \\
\hline \multirow{9}{*}{ rs4777498 } & \multirow{3}{*}{ Codominant } & $\mathrm{A} / \mathrm{A}$ & $188(66 \%)$ & $163(66 \%)$ & 1 & \multirow{3}{*}{0.1} & \multirow{3}{*}{736.2} & \multirow{3}{*}{749} \\
\hline & & $\mathrm{C} / \mathrm{A}$ & $89(31.2 \%)$ & $68(27.5 \%)$ & $0.88(0.60-1.29)$ & & & \\
\hline & & $\mathrm{C} / \mathrm{C}$ & $8(2.8 \%)$ & $16(6.5 \%)$ & $2.31(0.96-5.53)$ & & & \\
\hline & \multirow{2}{*}{ Dominant } & $\mathrm{A} / \mathrm{A}$ & $188(66 \%)$ & $163(66 \%)$ & 1 & \multirow{2}{*}{0.99} & \multirow{2}{*}{738.8} & \multirow{2}{*}{747.3} \\
\hline & & $\mathrm{C} / \mathrm{A}-\mathrm{C} / \mathrm{C}$ & $97(34 \%)$ & $84(34 \%)$ & $1.00(0.70-1.43)$ & & & \\
\hline & \multirow{2}{*}{ Recessive } & $\mathrm{A} / \mathrm{A}-\mathrm{C} / \mathrm{A}$ & $277(97.2 \%)$ & $231(93.5 \%)$ & 1 & \multirow{2}{*}{0.041} & \multirow{2}{*}{734.6} & 7432 \\
\hline & & $\mathrm{C} / \mathrm{C}$ & $8(2.8 \%)$ & $16(6.5 \%)$ & $2.40(1.01-5.70)$ & & & 145.2 \\
\hline & domina & $\mathrm{A} / \mathrm{A}-\mathrm{C} / \mathrm{C}$ & $196(68.8 \%)$ & $179(72.5 \%)$ & 1 & 035 & 7379 & 7465 \\
\hline & Uverdommant & $\mathrm{C} / \mathrm{A}$ & $89(31.2 \%)$ & $68(27.5 \%)$ & $0.84(0.57-1.22)$ & 0.35 & 131.9 & 140.5 \\
\hline & Log-additive & --- & --- & --- & $1.12(0.83-1.51)$ & 0.46 & 738.3 & 746.8 \\
\hline & & $\mathrm{T} / \mathrm{T}$ & $145(50.9 \%)$ & $102(41.3 \%)$ & 1 & & & \\
\hline & Codominant & $\mathrm{T} / \mathrm{C}$ & $113(39.6 \%)$ & $112(45.3 \%)$ & $1.41(0.98-2.03)$ & 0.067 & 735.4 & 748.2 \\
\hline & & $\mathrm{C} / \mathrm{C}$ & $27(9.5 \%)$ & $33(13.4 \%)$ & $1.74(0.98-3.07)$ & & & \\
\hline & Dominan & $\mathrm{T} / \mathrm{T}$ & $145(50.9 \%)$ & $102(41.3 \%)$ & 1 & 027 & 339 & 425 \\
\hline$r<3$ & Dommant & $\mathrm{T} / \mathrm{C}-\mathrm{C} / \mathrm{C}$ & $140(49.1 \%)$ & $145(58.7 \%)$ & $1.47(1.04-2.08)$ & 0.021 & 150.9 & 142.5 \\
\hline IS5094 & Recescive & $\mathrm{T} / \mathrm{T}-\mathrm{T} / \mathrm{C}$ & $258(90.5 \%)$ & $214(86.6 \%)$ & 1 & 0.16 & 736.8 & 745.4 \\
\hline & Recessive & $\mathrm{C} / \mathrm{C}$ & $27(9.5 \%)$ & $33(13.4 \%)$ & $1.47(0.86-2.53)$ & & & \\
\hline & Overdominant & $\mathrm{T} / \mathrm{T}-\mathrm{C} / \mathrm{C}$ & $172(60.4 \%)$ & $135(54.7 \%)$ & 1 & 018 & 737 & 456 \\
\hline & everuomintant & $\mathrm{T} / \mathrm{C}$ & $113(39.6 \%)$ & $112(45.3 \%)$ & $1.26(0.89-1.78)$ & 0.10 & IIJ & $1+3.0$ \\
\hline & Log-additive & --- & --- & --- & $1.35(1.04-1.74)$ & 0.021 & 733.5 & 742 \\
\hline
\end{tabular}

Abbreviations: SNPs: Single nucleotide polymorphisms; OR: Odds ratio; CI: Confidence interval.

$p$-values were calculated using Pearson's $\chi^{2}$ test. Values of $p<0.05$ were considered statistically significant.

Table 3: Association between SNPs and different clinical CC subtypes

\begin{tabular}{lcccccccc}
\hline & \multicolumn{3}{c}{ Clinical Stages } & & \multicolumn{3}{c}{ Subtypes } \\
\cline { 2 - 10 } SNPs & I-II & & III-IV & & \multicolumn{2}{c}{ squamous carcinoma } & adenocarcinoma \\
\cline { 2 - 10 } & OR (95\%CI) & $\mathbf{p}$ & OR (95\%CI) & $\mathbf{p}$ & OR (95\%CI) & p & OR (95\%CI) & p \\
\hline rs512715 & $1.23(0.90-1.68)$ & 0.187 & $1.41(0.98-2.02)$ & 0.060 & $1.37(1.05-1.79)$ & 0.021 & $0.93(0.30-2.94)$ & 0.906 \\
rs3094 & $1.26(0.93-1.70)$ & 0.136 & $1.51(1.06-2.14)$ & 0.021 & $1.31(1.01-1.70)$ & 0.043 & $4.02(1.44-11.24)$ & 0.004 \\
rs8004334 & $1.07(0.81-1.43)$ & 0.624 & $1.60(1.15-2.24)$ & 0.006 & $1.27(0.99-1.63)$ & 0.056 & $0.98(0.35-2.74)$ & 0.974 \\
\hline
\end{tabular}

Abbreviations: SNPs: Single nucleotide polymorphisms; OR: Odds ratio; CI: Confidence interval.

$p$-values were calculated using Pearson's $\chi^{2}$ test. Values of $p<0.05$ were considered statistically significant. 
Table 4: Primers used for this study

\begin{tabular}{|c|c|c|c|}
\hline SNP_ID & 1st-PCRP & 2nd-PCRP & UEP_SEQ \\
\hline rs2285332 & $\begin{array}{c}\text { ACGTTGGATGTGAGCTGC } \\
\text { TTCAGTGTAACC }\end{array}$ & $\begin{array}{l}\text { ACGTTGGATGCTTTG } \\
\text { CCAAAAGCTAAGCAG }\end{array}$ & gGCCAAAAGCTAAGCAGTGGTGAA \\
\hline rs 701848 & $\begin{array}{c}\text { ACGTTGGATGATAGTGCTC } \\
\text { CCCCGAGTTG }\end{array}$ & $\begin{array}{l}\text { ACGTTGGATGCTCCG } \\
\text { CTTAAAATCGTATGC }\end{array}$ & TGATTTTTTTTAAGAAGTGAAATTGA \\
\hline rs 11202607 & $\begin{array}{c}\text { ACGTTGGATGTATTTATG } \\
\text { ACCTGGCCCTCC }\end{array}$ & $\begin{array}{c}\text { ACGTTGGATGTTACAA } \\
\text { TTTCGGGCACCGCA }\end{array}$ & cTTCGGGCACCGCATATTAAAA \\
\hline rs680413 & $\begin{array}{c}\text { ACGTTGGATGCCTAGA } \\
\text { CCTAGTCTCCTTGC }\end{array}$ & $\begin{array}{l}\text { ACGTTGGATGGGGAG } \\
\text { AGATGACTGAGTTAG }\end{array}$ & ggTGACTGAGTTAGATGAGAC \\
\hline rs512715 & $\begin{array}{l}\text { ACGTTGGATGAACAG } \\
\text { CCACTCGGCTTACTG }\end{array}$ & $\begin{array}{l}\text { ACGTTGGATGCCCTT } \\
\text { СТTCСTCCCTTTAAC }\end{array}$ & AАСТTATССАТТСАСТТААААСАТТА \\
\hline rs1133822 & $\begin{array}{l}\text { ACGTTGGATGCCTTC } \\
\text { GTTCTCCTTCGTTTG }\end{array}$ & $\begin{array}{c}\text { ACGTTGGATGTTTC } \\
\text { TCTGCTCTGGCAGACC }\end{array}$ & gGGGCACCACTTGTCACGG \\
\hline rs4777498 & $\begin{array}{c}\text { ACGTTGGATGGGATTG } \\
\text { TGGATTGTGGGTTC }\end{array}$ & $\begin{array}{c}\text { ACGTTGGATGTGAG } \\
\text { GTCTAGGCTCACATGC }\end{array}$ & GCTCACATGCAGGTAAT \\
\hline rs3094 & $\begin{array}{c}\text { ACGTTGGATGGATTATC } \\
\text { GCGAGTGGTTGAC }\end{array}$ & $\begin{array}{c}\text { ACGTTGGATGAATGAG } \\
\text { CTGAGGAGACAGAG }\end{array}$ & ccGCTGAGGAGACAGAGCCTGGG \\
\hline rs8004334 & $\begin{array}{c}\text { ACGTTGGATGACTAAA } \\
\text { GGCCTCCCAAGTCA }\end{array}$ & $\begin{array}{l}\text { ACGTTGGATGTCCTA } \\
\text { CTGGGCCTTTGCTTC }\end{array}$ & aTTTGCTTCCCCCACAAATTAAAT \\
\hline rs3733839 & $\begin{array}{c}\text { ACGTTGGATGCCATGC } \\
\text { AACCAATTCCATCC }\end{array}$ & $\begin{array}{c}\text { ACGTTGGATGGTCTCC } \\
\text { TGACTTGTCAAGGC }\end{array}$ & TCCTCTGCACCTGTCCT \\
\hline
\end{tabular}

pri-miRNAs are processed by RNase III to form premiRNAs exported to the cytosol, carried by exportin 5, after which the pre-miRNAs are processed by Dicer in the cytosol to mature miRNAs. One strand of the mature miRNA is then incorporated with RNAinduced silencing complex (RISC), directing it to target mRNA [8].

The minor allele "C" of rs512715 increased CC risk in the allele, codominant, dominant, overdominant and log-additive models. Rs512715 belongs to NEAT1, which is regulated by hsa-mir-342-3p. We know of no other study relating NEAT1 to CC risk, though a Chinese study found a relationship between NEAT1 and bladder cancer $[9,10]$. In addition, an American study found hsa-mir$342-3 p$ to be related to irritable bowel syndrome [11]. In a German study, significant upregulation of hsa-miR-342$3 p$ was detected in the brains of macaques infected with bovine spongiform encephalopathy, and in a pilot study they also showed that hsa-miR-342-3p was upregulated in brain samples from humans with type 1 or type 2 sporadic Creutzfeldt-Jakob disease [12]. We have so far detected no direct evidence of a specific relationship between hsamiR-342-3p and CC, and we suggest that this miRNA likely plays a general role in the regulation of multiple target genes in disease. However, the detailed mechanism by which hsa-miR-342-3p exerts gene effects in CC deserves further investigation.
The minor allele "C" of rs4777498 increased CC risk in the recessive model. Rs4777498 belongs to CELF6, which is regulated by hsa-mir-375. An American study found that CELF6 is highly expressed in diencephalic nuclei and neuromodulatory cell populations of the mouse brain [13]. Previous studies also reported hsamir-375 to be related to pancreatic cancer and early stage breast cancer $[14,15]$. In breast cancer, higher levels of hsa-mir-375 were expressed in ER- $\alpha$-positive than ER$\alpha$-negative or normal cells, which led to the suggestion that hsa-miR-375 up-regulation is a key driver of cell proliferation and an early event in tumorigenesis in ER$\alpha$-positive tissues [16]. However, a detailed understanding of the mechanism by which hsa-mir-375 affects CC risks will require further investigation.

The minor allele " $\mathrm{C}$ " of rs3094 increased CC risk in the allele, dominant and log-additive models. In clinical stage III/IV patients, the minor allele "C" of rs3094 and minor allele " $C$ " of rs8004334 were associated with increased CC risk. Rs3094 belongs to RNASE4 while rs8004334 belong to $J D P 2$, and both are regulated by hsa-mir-590-5p. Previous studies showed RNASE4 to be associated with high-altitude adaptation, metabolic syndrome and neuron degeneration [17-19], while JDP2 was associated with heart failure [20]. Hsa-mir-590-5p is reportedly related to cardiac differentiation through down-regulation of TGFB signaling [21]. TGFB1-induced 
activation of Smad 2, -3, -4 leads to direct inhibition of STAT5 transactivation and STAT5-mediated transcription of downstream target genes, including miR-590 [22]. TGFB1 inhibits STAT5 expression at the protein level with no effect on mRNA expression. Whether there is a relationship between the mechanism of hsa-mir-590-5pmediated effects on $\mathrm{CC}$ risk and TGFB signaling warrants further investigation.

There are two intrinsic limitations to this study. 1) The sample size was not large enough to obtain illative combinatory associations between SNPs and CC. 2) Selection bias may be unavoidable since this was a hospital-based study. Therefore, larger well-designed studies combined with CC classification are needed to confirm the observed associations and clarify the potential biological mechanisms of these SNPs in CC.

In summary, we have identified significant associations between rs512715 (NEAT1), rs4777498 (CELF6), rs3094 (RNASE) and rs8004334 (JDP2) and CC risk in Xinjiang Uygur population.

\section{MATERIALS AND METHODS}

\section{Study participants}

A total of 532 subjects, including 247 patients with cervical cancer and 285 healthy women were recruited at the People's Hospital of Xinjiang Uyghur Autonomous Region between January 2014 and Jun 2016. The included patients were recently diagnosed with primary CC based on cervical biopsy with histopathological confirmation. We excluded patients with other cancers who underwent radiotherapy or chemotherapy. Controls were healthy, unrelated individuals selected randomly from the medical examination center of the hospital. All participants were women at least 18 years old in good mental condition who had at least three generations of paternal ancestry in their ethnicity (Xinjiang Uygur population). Tumors were staged according to International Federation of Gynecology and Obstetrics (FIGO) classification. Informed consent was obtained from all participants, and the study protocols were approved by the institutional review board of the People's Hospital of Xinjiang Uyghur Autonomous Region.

\section{SNP selection and genotyping}

Candidate SNPs were selected from among previously published polymorphisms associated with CC. Validated SNPs were selected with a MAF $>5 \%$ in the HapMap Asian population [23]. Venous blood samples (5 $\mathrm{ml}$ ) were collected from each patient during laboratory examination. Genomic DNA was extracted from whole blood samples using a Gold Mag-Mini Whole Blood Genomic DNA Purification Kit (version 3.0; TaKaRa, Japan) [24] and stored at $-80^{\circ} \mathrm{C}$ after centrifugation. DNA concentrations were evaluated using spectrometry (DU530 UV/VIS spectrophotometer, Beckman Instruments, Fullerton, CA, USA). We used Sequenom MassARRAY Assay Design 3.0 Software to design the Multiplexed SNP MassEXTEND assays [25]. SNP genotyping was done with a Sequenom MassARRAY RS1000 using the standard protocol recommended by the manufacturer [25]. The primer sequences used for genotyping are listed in Table 4. Data management and analyses were performed using Sequenom Typer 4.0 software as previously described $[25,26]$.

\section{Statistical analysis}

Statistical analyses were performed using Microsoft Excel (Redmond, WA, USA) and the SPSS 17.0 statistical package (SPSS, Chicago, IL, USA). All $p$ values in this study were two-sided, and $p \leq 0.05$ after Bonferroni correction was considered the statistical significance threshold [27]. An exact test was used to assess the departure of each SNP frequency from Hardy-Weinberg equilibrium (HWE) in the controls. We compared allele frequencies between cases and controls using the $\chi^{2}$ test. To assess the association of single SNPs with the risk of CC, five genetic models (codominant, dominant, recessive, over-dominant and log-additive) were applied using PLINK software (http://www.cog-genomics.org/plink2/). Odds ratios (ORs), 95\% confidence intervals (95\% CIs), and $p$ values were calculated using unconditional logistic regression analysis [28-30].

\section{ACKNOWLEDGMENTS}

This work was supported by the project of International Cooperation in Science and Technology of Shaanxi Province (No.2013KW-27-01), the Fundamental Research Funds for the Central Universities (No. XJJ2015094).

\section{CONFLICTS OF INTEREST}

The authors declare no conflicts of interest.

\section{REFERENCES}

1. Kontostathi G, Zoidakis J, Anagnou NP, Pappa KI, Vlahou A, Makridakis M. Proteomics approaches in cervical cancer: focus on the discovery of biomarkers for diagnosis and drug treatment monitoring. Expert review of proteomics. 2016.

2. Ferlay J, Soerjomataram I, Dikshit R, Eser S, Mathers C, Rebelo M, Parkin DM, Forman D, Bray F. Cancer incidence and mortality worldwide: sources, methods and major patterns in GLOBOCAN 2012. International journal of cancer. 2015; 136:E359-386. 
3. Bernard HU, Burk RD, Chen Z, van Doorslaer $K$, zur Hausen H, de Villiers EM. Classification of papillomaviruses (PVs) based on $189 \mathrm{PV}$ types and proposal of taxonomic amendments. Virology. 2010; 401:70-79.

4. Thakur S, Grover RK, Gupta S, Yadav AK, Das BC. Identification of Specific miRNA Signature in Paired Sera and Tissue Samples of Indian Women with Triple Negative Breast Cancer. PloS one. 2016; 11:e0158946.

5. Kasimanickam V, Kastelic J. Circulating cell-free mature microRNAs and their target gene prediction in bovine metritis. Scientific reports. 2016; 6:29509.

6. Vergho DC, Kneitz S, Kalogirou C, Burger M, Krebs M, Rosenwald A, Spahn M, Loser A, Kocot A, Riedmiller H, Kneitz B. Impact of miR-21, miR-126 and miR-221 as prognostic factors of clear cell renal cell carcinoma with tumor thrombus of the inferior vena cava. PloS one. 2014; 9:e109877.

7. Qiu M, Liu L, Chen L, Tan G, Liang Z, Wang K, Liu J, Chen H. microRNA-183 plays as oncogenes by increasing cell proliferation, migration and invasion via targeting protein phosphatase $2 \mathrm{~A}$ in renal cancer cells. Biochemical and biophysical research communications. 2014; 452:163-169.

8. Lee Y, Jeon K, Lee JT, Kim S, Kim VN. MicroRNA maturation: stepwise processing and subcellular localization. The EMBO journal. 2002; 21:4663-4670.

9. XianGuo C, ZongYao H, Jun Z, Song F, GuangYue L, LiGang Z, KaiPing Z, YangYang Z, ChaoZhao L. Promoting progression and clinicopathological significance of NEAT1 over-expression in bladder cancer. Oncotarget. 2016 Jun 15. doi: 10.18632/oncotarget.10084. [Epub ahead of print]

10. Gheinani AH, Burkhard FC, Monastyrskaya K. Deciphering microRNA code in pain and inflammation: lessons from bladder pain syndrome. Cellular and molecular life sciences: CMLS. 2013; 70:3773-3789.

11. Fourie NH, Peace RM, Abey SK, Sherwin LB, RahimWilliams B, Smyser PA, Wiley JW, Henderson WA. Elevated circulating miR-150 and miR-342-3p in patients with irritable bowel syndrome. Experimental and molecular pathology. 2014; 96:422-425.

12. Montag J, Hitt R, Opitz L, Schulz-Schaeffer WJ, Hunsmann G, Motzkus D. Upregulation of miRNA hsa-miR-342-3p in experimental and idiopathic prion disease. Molecular neurodegeneration. 2009; 4:36.

13. Maloney SE, Khangura E, Dougherty JD. The RNA-binding protein Celf6 is highly expressed in diencephalic nuclei and neuromodulatory cell populations of the mouse brain. Brain structure \& function. 2016; 221:1809-1831.

14. Lee KH, Lee JK, Choi DW, Do IG, Sohn I, Jang KT, Jung $\mathrm{SH}$, Heo JS, Choi SH, Lee KT. Postoperative prognosis prediction of pancreatic cancer with seven microRNAs. Pancreas. 2015; 44:764-768.

15. Zehentmayr F, Hauser-Kronberger C, Zellinger B, Hlubek F, Schuster C, Bodenhofer U, Fastner G, Deutschmann H,
Steininger P, Reitsamer R, Fischer T, Sedlmayer F. HsamiR-375 is a predictor of local control in early stage breast cancer. Clinical epigenetics. 2016; 8:28.

16. Jonsdottir K, Janssen SR, Da Rosa FC, Gudlaugsson E, Skaland I, Baak JP, Janssen EA. Validation of expression patterns for nine miRNAs in 204 lymph-node negative breast cancers. PloS one. 2012; 7:e48692.

17. Yu L, Wang GD, Ruan J, Chen YB, Yang CP, Cao X, Wu H, Liu YH, Du ZL, Wang XP, Yang J, Cheng SC, Zhong L, et al. Genomic analysis of snub-nosed monkeys (Rhinopithecus) identifies genes and processes related to high-altitude adaptation. Nature genetics. 2016.

18. Lan X, Li D, Zhong B, Ren J, Wang X, Sun Q, Li Y, Liu L, Liu L, Lu S. Identification of differentially expressed genes related to metabolic syndrome induced with high-fat diet in E3 rats. Experimental biology and medicine. 2015; 240:235-241.

19. Li S, Sheng J, Hu JK, Yu W, Kishikawa H, Hu MG, Shima K, Wu D, Xu Z, Xin W, Sims KB, Landers JE, Brown RH, $\mathrm{Jr}$., $\mathrm{Hu}$ GF. Ribonuclease 4 protects neuron degeneration by promoting angiogenesis, neurogenesis, and neuronal survival under stress. Angiogenesis. 2013; 16:387-404.

20. Maciejak A, Kiliszek M, Michalak M, Tulacz D, Opolski G, Matlak K, Dobrzycki S, Segiet A, Gora M, Burzynska B. Gene expression profiling reveals potential prognostic biomarkers associated with the progression of heart failure. Genome medicine. 2015; 7:26.

21. Ekhteraei-Tousi S, Mohammad-Soltani B, Sadeghizadeh M, Mowla SJ, Parsi S, Soleimani M. Inhibitory effect of hsa-miR-590-5p on cardiosphere-derived stem cells differentiation through downregulation of TGFB signaling. Journal of cellular biochemistry. 2015; 116:179-191.

22. Cocolakis E, Dai M, Drevet L, Ho J, Haines E, Ali S, Lebrun JJ. Smad signaling antagonizes STAT5mediated gene transcription and mammary epithelial cell differentiation. The Journal of biological chemistry. 2008; 283:1293-1307.

23. Bouatia-Naji N, Marchand M, Cavalcanti-Proenca C, Daghmoun S, Durand E, Tichet J, Marre M, Balkau B, Froguel P, Levy-Marchal C. Smallness for gestational age interacts with high mobility group A2 gene genetic variation to modulate height. European journal of endocrinology / European Federation of Endocrine Societies. 2009; 160:557-560.

24. Vandewoestyne M, Van Nieuwerburgh F, Van Hoofstat D, Deforce D. Evaluation of three DNA extraction protocols for forensic STR typing after laser capture microdissection. Forensic science international Genetics. 2012; 6:258-262.

25. Gabriel S, Ziaugra L. SNP genotyping using Sequenom MassARRAY 7K platform. Current protocols in human genetics. 2004:2.12. 11-12.12. 16.

26. Thomas RK, Baker AC, DeBiasi RM, Winckler W, LaFramboise T, Lin WM, Wang M, Feng W, Zander T, MacConaill LE. High-throughput oncogene mutation 
profiling in human cancer. Nature genetics. 2007; 39:347-351.

27. Song MK, Lin FC, Ward SE, Fine JP. Composite Variables: When and How. Nurs Res. 2012.

28. Adamec C. Example of the use of the nonparametric test. Test $\mathrm{x} 2$ for comparison of 2 independent examples. Ceskoslovenske zdravotnictvi. 1964; 12:613-619.

29. Bland JM, Altman DG. The odds ratio. Bmj. 2000; 320:1468.
30. Purcell S, Neale B, Todd-Brown K, Thomas L, Ferreira MA, Bender D, Maller J, Sklar P, De Bakker PI, Daly MJ. PLINK: a tool set for whole-genome association and population-based linkage analyses. The American Journal of Human Genetics. 2007; 81:559-575. 